\title{
Concepts \& tools for manufacturing planning, control and performance management
}

\author{
$H$. Lengning \\ SOFLEX Fertigungssteuerungs-GmbH, Etzwiesenstraße 25 \\ 72108 Rottenburg-Hailfingen \\ Tel: +49745794550 \\ Fax: +497457945510 \\ e-mail: horst.lengning@soflex.de
}

\begin{abstract}
This description contains an overview of the scope of functions and the structure of Production Management System. Apart from the description of the practical use of this product, information about the further possibilities to extend the system and to integrate it in a given environment are described as well.
\end{abstract}

\section{Keywords}

PMS - Production Management System, Status Management, Production control, Occupancy management, Optimization of the production processes 
Looking at the evolution of production control technology in recent years one might come to the conclusion that is has lost significance compared to the status of the mid eighties. The idea of CIM and the euphoria which came with it the main was to reach higher automation of production flows by use of computers and to create a manufacturing environment few or even without personnel has been confronted with reality. Dominating the variants of production control technology, graphical production monitoring systems in manual conventional environment and production control systems for complex highly automated production plants have not succeeded in reaching greater importance in the nineties. The trend towards simple control mechanisms and small cell solutions which have increased due to the growing importance of teamwork.

The ever shorter innovation cycles demanded by the market lead to shorter product life times and to minimisation of storage cause the production of smaller lots. This increase the number of orders to produce within a special period of time. It increase as well the complexity of production processes. The dynamic as well as the number of the processes which have to be produced parallel have grown. Production units are confronted with harder requirements concerning shorter delays and "Just- in- time" production, from transportation directly to assembly.

\section{Actual Situation}

\section{- Modification of the Production-Processes}

$\square$ increasing orders for the production

$\square$ fewer parts per order

\section{- Date and Quality}

$\square$ short-term deadlines

$\square$ high Quality requirement

O SOFLEX 2

The most important point for evaluating production units are the keeping of delays and quality production. All other factors like machine utilisation or optimal use resources are imperial compared to these criteria.

What can be done to face these requirements? There are two possibilities for the area of production:

- Improving production technology 
- Improving production organisation

Production automation and production organisation are the two basic principles for the restructuring of production units.

\section{Finding Solutions}

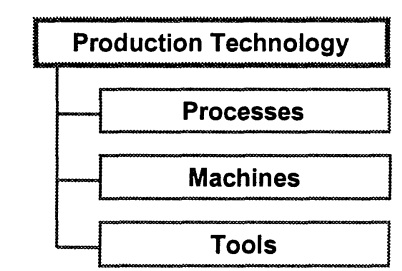

Progress is not only made by technological inventions and new developments

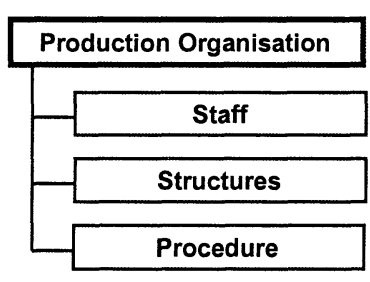

but to a great extent by the resulting changes in organisation.

Both subjects have long been considered as being independent from each other. However, with the cost-optimised production becoming more and more an absolute necessity, it becomes evident that production automation does not lead to the hoped-for cost cutting automatically. Every technology requires an adequate organisation of the production environment if the user is to enjoy the benefits completely.

Consequently for production units already working the potential for costcutting improvement should be found mainly in organisational processes, as the technology used is defined by the installed machines. Basically there are two fields where improvement is possible:

- Optimisation of the production process

- Efficient use of the production installations and the production resources

In production organisation as the whole some IT-systems have found their place. Production planning systems (ERP) with their most important example SAP-R3, the growing importance of CAD/CAM and NC-programming systems show that the described trends are also valid for production companies. New computer technology, decentralised PCs instead of main framecomputers, other operating systems, Windows NT, Linux, and the problem of the year 2000 and the EURO conversion have given these systems grown importance.

It is evident that there is large gap between these systems on planning level and the systems on the operative shop floor level. 
The field of near shop floor production organisation is on the one hand the binding element between the level of planning and work preparation and the level of production on the other hand it contains far reaching functions for control and optimisation of production processes.

\section{Utilization and Interfaces}

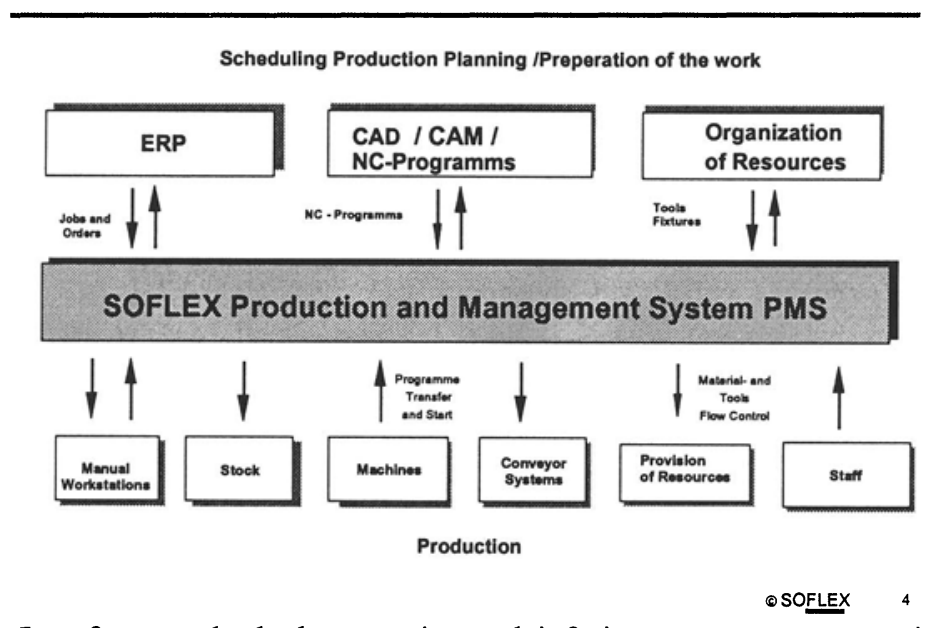

Interfaces to both the superior and inferior systems are very important here. Interfaces mean partly automatised exchange of information between the systems.

\section{Tasks}

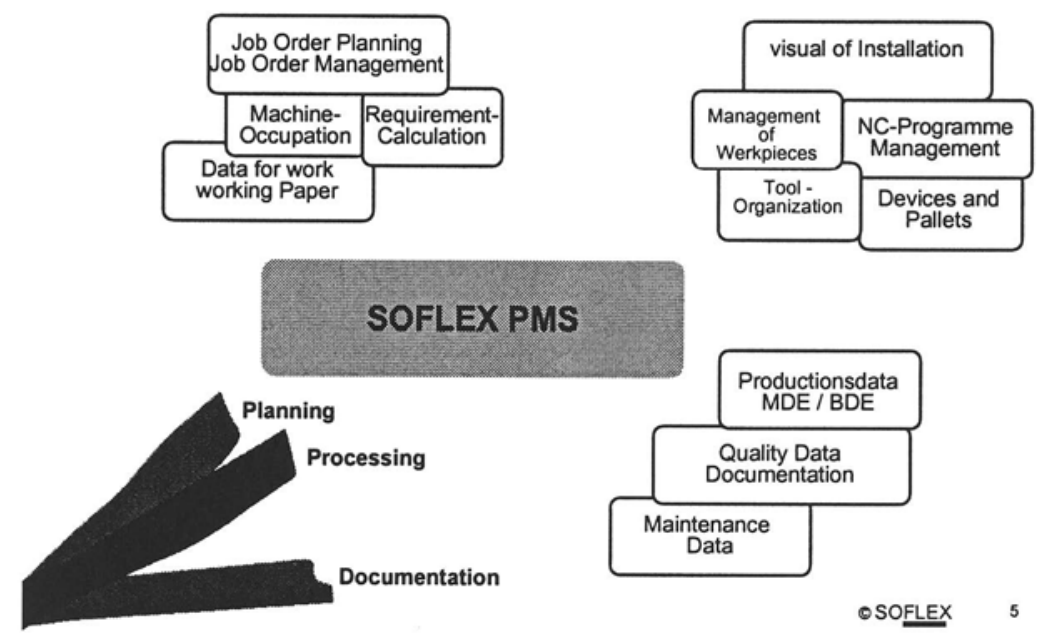

For example transfer of order data from ERP or status messages on the machine control. Although the physical coupling there are some standard used now a days 
the procedures for information transfer and information content are not standardised and must be optimised specifically.

The main task of this field is carrying out production orders with the preference to do this with respect of the delay in delivery and quality demanded by the customer. Thus it is important to manage the appropriate data. Orders, operation plans and operation data, like NC-programs, test instructions, drawing etc. , are the basic information of scheduling.

The scheduling defines the sequence of operation steps at the machines and the work places. In addition to this default data it needs information about machines and work places for their occupation and their status about the resources currently used as well as about the work and shift times. The calculation of requirements of the resources i.e. the information at what time such resources are used and are necessary for carrying out the planned tasks add up to the task of planning.

In the field of controlling the provision of control instructions for manual and automatised procedures is the vital part of production organisation. Parts, tools fixtures and operation data as well must be provided to the work places in time. The visualisation of the plant which gives a complete picture of the production area serves as an important information basis.

The recording of events, the logging of procedures and the storing data in long term statistics is the third main task and is designated with the concept documentation.

All three tasks planning, controlling and documentation appear in different varying importance depending on the degree of automation and the requirements.

One of the most important tasks of production control systems now a days is to provide information which answers the every day questions near workshop level production organisation. The questions and information resulting from them can be classified as follows:

- Planning information (What happens if?)

- Status information (What object is where and what status?)

- Logging information ( How was a special operation carried out?)

This information must be provided by the system in time and without long delay so that the person responsible for the production can use it for his decisions.

The following explanation contains an overview of the functions about a Production Management System (PMS) of the practical use of this product, integrated in a reality environment .

The PMS has been specified with nine major objectives in mind: 


\section{Functions}

- System overview with online display of status and occupation

- Analysis of production time

- Management of operation plans

- Daily request of parts

- Production scheduling

- Statistical ananlysis of production data

- Capture and analysis of machine data

- Fault and weak point analysis

- Information and lists sent from and to SAP-R3

Online - Production line overview

\section{PMS Line overview detail on top level}

\section{Online-Production line overview}

Status within machine

Part status: Type/OP/No.

Machine status: $S=P$ Production

$\mathrm{T}=$ Cycle time $\quad \mathrm{B}=$ operator call

Part prod. default: M=machine no.

Shaddow $=\%$ in progress

Status within buffer

Part status Type/OP/No.

Part status Type/OP/No.

Part status Type/OP/No.

Degree of charge: $L=$ Buffer no.

Shaddow $=\%$ degree of charge

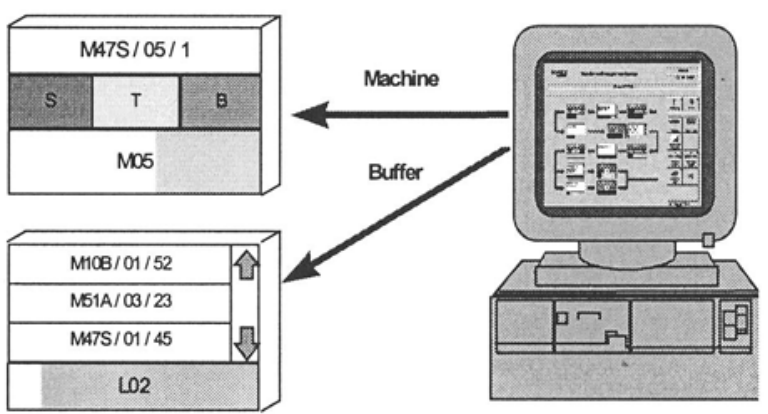

CSOFLEX 7

Visualising of the production sequence and the machine status of the relevant production line. This visualising is carried out using a Graphic layout of the production line:

- Part status

- Machine status

- Part production default

- Buffer status 
Line overview have detailed information of work piece with status information. Additional information is available like work piece type, operation number and number of parts. Different colour on the status can define different work piece status, i.e. colour red $=$ scrap. Shadow within the status field inform about $\%$ degree of buffer space.

\section{Analysis of production time}

Chronological analysis of passed events
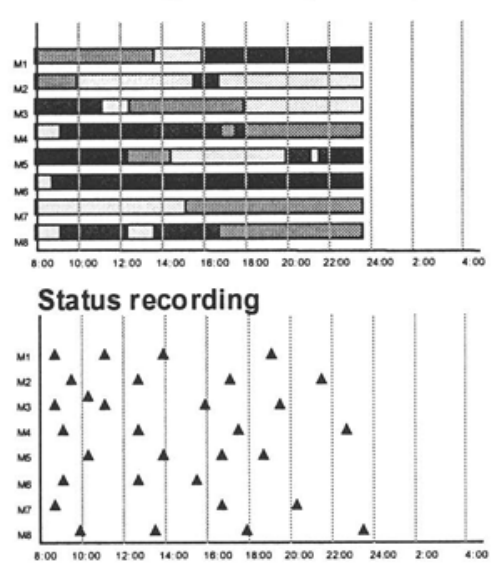

Recording of check results

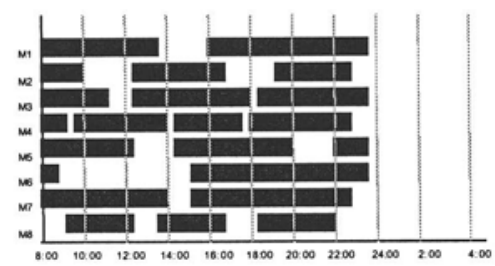

Production periods

Current status recording can be displayed online the machine level.

- Machine status

- Duration of machine status

The line review provides an opportunity to observe the progress of the machine status over a pre-selectable previous period using a bar chart. The relevant machine status is shown via the different coloured bar segments. For example blue $=$ production and another colour different error message.

Error message statistic will be available on operator request for selected machine(s) and unit(s).

Time utilisation is represented in hours over all production and non-production conditions for the individual machines. Representation with several machines or the whole line in a diagram.

Pre-selectable time pattern: Shift, day, week, month or year.

\section{Management of operation plans}

The structure of the management operation system:

Regarding the Machine Shop and the SAP is as a middle step the PMS (Production management system) 
On PMS, all data is collected from the machine or set by the operator within the machine area stored into a database. From there the evaluations can be made by MS-Windows standard tools or the information can be sent to SAP for reporting purpose.

PMS Order handling

PMS order handling can run standalone within PMS to handle different requests within part production and can have on special request an interface to SAP.

On lowest level work piece information should be available within each PLC,

\section{PMS functional structure}

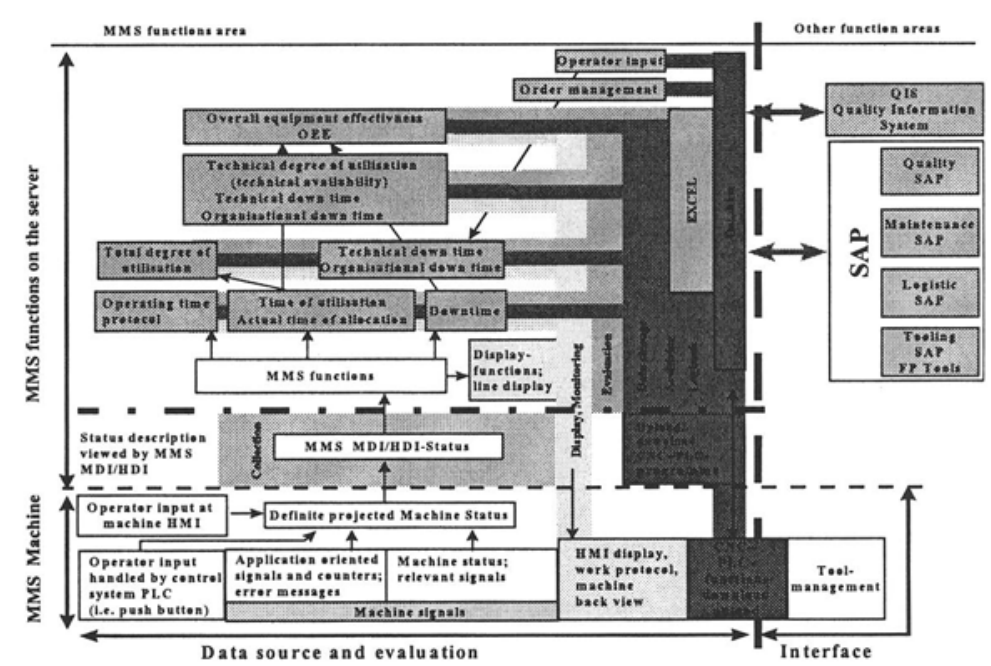

온EX

i.e. part type, number of parts, part counter, order information, operation, parts status. These data will be held within each PLC and can be request from other master PLC systems for a data collection.

PMS functions can collect work piece information on request from selected PLCs within a line over the network. PMS will control part production by order default. At the end of a line work pieces are grouped by order. The order information can be sent to other IT-Systems, i.e. SAP on request.

The parts flow in the production line is based on transport batches of specific part types (e.g. containers or pallets which can be loaded with a specific number of parts). For organisational reasons (easy handling by the workers, identification, etc. ) and conditions imposed by the technical proceedings (no buffer place for orderspecific transport batches), it is not possible to apply an order-related parts flow. 
The parts flow control of the PMS is based on day-specific parts output targets for the preparation of finished part types. Taking this and the part-type-specific operation plans into account, the PMS is able to calculate daily parts output target for every individual machine in the production line. The workers use these directions about the output targets to get the information what parts should be brought to the machines.

A "day order" is created from the individual orders of SAP on the basis of the part type and the production delay. These "day orders" are transferred to the PMS, and can be displayed, integrates them in its day-related parts output targets. In addition these targets can have relation to the order step transferred from SAP. The feedback of the production process can be based on these parts output targets, presuming a sequential processing of the "day orders" for every part type.

\section{PMS Hardware proposition}

- 1 Pentium II Processor with $233 \mathrm{MHz}$ and $128 \mathrm{MB}$ RAM or better

- 9 GB Disk drives, USV, DAT-Streamer, CD-ROM, disk shadowing

\section{PMS Interfaces to other IT-systems}

PMS interfaces to other IT-systems are possible-feasibility of know user requirements will be defined and detailed within final specification- and be handled with SOFLEX common software drivers.

\section{Maintenance common requirements}

PMS will assist SAP module functions. All maintenance fault conditions are send from PMS to SAP.

Within SAP Maintenance module the maintenance periods and activities can be planned.

\section{Advantages}

- Parts production as required

$\checkmark$ Quick realization of faults

- Constant check of cycle time deviations

- Continuous improvement by fault and weak point analysis

- Elimination of overstocks 


\section{Important characteristics}

$\checkmark$ Open architecture

Accepted hard-

and software standards

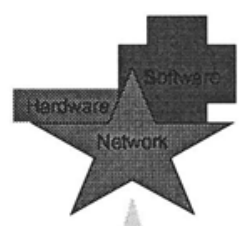

- Standardized interfaces

- High availability

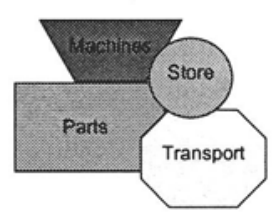

\section{PMS Quality-interface}

๑) SOFLEX

Between PMS and SAP QS-modules data connections are planned. All quality planning functions and gauge/measurement system evaluations are realised on QSsystems standard.

\section{BIOGRAPHY}

Mr. Horst Lengning is responsible for marketing and sales at SOFLEX. After his apprenticeship he worked with IBM in Germany and in the USA in different departments and finally specialized in marketing and sales. 